\title{
Influence of Exercise Classics on the Ability to Switch the Attention of Schoolchildren Aged 9-10 Years
}

\author{
Polevoy G.G. \\ Candidate of Pedagogical Sciences, Associate Professor, Department of Physical Education, \\ Moscow Aviation Institute (National Research University), Moscow, Russia
}

\begin{abstract}
Background: The problem of switching the attention of schoolchildren can be solved by exercises in physical education classes at school.

Aim: To determine the influence of exercise Classics on the ability of schoolchildren to switch their attention at the age of 9-10 years.

Method: The study was conducted over a period of 9 months, in which 40 9-10-year-olds took part. Physical education classes were held 2 times a week for 40 minutes each lesson. The level of development of coordination abilities was assessed on the «Shuttle run» test, and the indicators of attention switching on the «Method of Numbers» test. The programs bio-stat 2009, Microsoft excel 2016 and t-student were used for mathematical and statistical processing of results.

Results: Before the beginning of the pedagogical experiment, the indicators of school children between the groups did not have significant differences $(\mathrm{P}>0.05)$. After the end of the study, the indicators in both groups improved. In CG, in the «Shuttle run» test, the indicators improved from $10.2 \pm 0.6$ to $9.9 \pm 0.5$ ( $\mathrm{P}>0.05)$, and in the test for the level of attention switching, the indicators improved by $5.4 \%$ (P>0.05). In EG, in the «Shuttle run $3 \times 10 \mathrm{~m}$ » test, the indicators improved from $9.9 \pm 0.5$ to $8.5 \pm 0.4(\mathrm{P}<0.05)$, and in the «Method of Numbers» test, the indicators improved by $26.6 \%$. These results indicate the effectiveness of using exercise Classics in physical education lessons in working with younger schoolchildren.
\end{abstract}

Conclusion: If schoolchildren will perform exercise Classics in physical education classes at school, they will improve not only coordination abilities, but also attention switching indicators.

Keywords: Attention switching, coordination abilities, school children, physical education, Classics.

\section{Introduction}

At the present stage of development of society, one of the most important tasks is the optimal level of motor activity, motor mode during the day. Unfortunately,

\section{Corresponding Author:}

\section{Polevoy G.G.}

Candidate of Pedagogical Sciences, Associate

Professor, Department of Physical Education,

Moscow Aviation Institute (National Research

University), Moscow, Russia

e-mail: g.g.polevoy@gmail.com every year more and more children with disabilities enter the first classes in a state of health, while the main problem is a lack of motor activity. It was found that the lack of motor activity significantly worsens the health of the growing human body, weakens its defenses, and does not provide full physical development. Diseases of the heart, blood vessels, lung system, and some others are progressing and becoming younger. It is impossible to fully develop schoolchildren without physical education. Physical education is an integral part of the modern Russian education system. The main form of physical exercises in school is a physical culture lesson. During the lesson, the teacher forms schoolchildren interest in physical exercises, encourages them to be 
active. The main task is to ensure that children, starting from their earliest childhood, grow up healthy, strong, and harmoniously developed. Physical culture plays an important role in improving a person's health ${ }^{1-2}$.

Schoolchildren receive the necessary minimum of knowledge, skills and abilities provided for in the school curriculum, and increase their level of physical development ${ }^{3}$. One of the problems of implementing modern programs is the lack of a comfortable gym for a lesson in physical culture. Some authors suggest replacing the standard program with modern method ${ }^{4-5}$. In our opinion, the more correct option is only to add the standard program. The effectiveness of implementing exercise Classics in physical education classes at school has been proved ${ }^{6}$.

An individual-differentiated approach to exercise Classics is very important. Thanks to this, schoolchildren can realize the reserve potential of their body, meet the needs for physical and motor activity ${ }^{7-8}$.

Exercise Classics allows you to develop coordination abilities - this is the ability of a person to quickly master new movements and solve motor problems that arise in unexpected and changing situations. A high level of development of coordination abilities allows you to save movement, strength, and time. The efficiency and rationality of human motor actions increases simultaneously with an increase in the indicators of coordination abilities ${ }^{9-11}$. It should be noted that the sensitive period for the development of most conditioning and coordination abilities is primary school age. The effect of developing such abilities will be higher if you purposefully influence them in early school age ${ }^{12-13}$.

Motor activity has a positive effect on the mental processes of schoolchildren, it improves their thinking processes ${ }^{14-15}$. Some studies confirm the effectiveness of physical education for obtaining positive grades in other subjects ${ }^{16}$.

Thus, the aim of the study is to determine the influence of exercise Classics on the ability of schoolchildren to switch their attention at the age of 9-10 years.

\section{Material and Method}

Participants: 40 children, boys and girls 9-10 years old took part in the pedagogical experiment. At the time of the study, the schoolchildren were in the third grade at normal school No. 60 (Russia). Children who had good health indicators and were able to engage in physical education at school were admitted to the study.

All procedures met the ethical standards of the 1964 Declaration of Helsinki. Informed consent was obtained from all parents of the children included in the study.

Procedure: The pedagogical experiment lasted from September to may (9 months). Classes for schoolchildren were held twice a week for 40 minutes. There were 56 physical education classes in total.

\section{Before starting the study, two groups were formed:}

1. Control group (CG) - children of class 3A (20 people). During the school year, schoolchildren were engaged in a standard physical education program at school ${ }^{3}$.

2. Experimental group (EG) - children of class $3 B(20$ people). During the school year, schoolchildren were engaged in the usual program and additionally performed exercise Classics at each physical education lesson (table 1).

\section{Table 1. Exercise "Classic's"}

\begin{tabular}{|l|l|l|}
\hline 1 & 5 & 6 \\
\hline 4 & 8 & 2 \\
\hline 9 & 7 & 3 \\
\hline
\end{tabular}

Exercise Classics: In the gym, there are three large squares on the floor. The side of one square is $180 \mathrm{~cm}$. Inside each large square there are nine small squares, the side of the small square is $60 \mathrm{~cm}$. Inside each small square are numbers from 1 to 9 . 
Task: the schoolchild must use jumps from square to square to get from number 1 to number 2 , then to number 3 , and so on, to number 9 . After that, it should jump on the same squares in reverse order (from number 9 to number 1). You can move around the squares in any way (from one leg to the other, jump on one leg or on two). If the schoolchild makes a mistake, he returns to the previous square. During the lesson, each schoolchild must overcome three large squares. The numbers in the squares must be changed by the teacher before each lesson. You can perform the exercise in any part of the lesson.

Before and after the pedagogical experiment all schoolchildren took control tests:

1. "Shuttle run $3 \times 10 \mathrm{~m}$ " (indicator of coordination abilities) $)^{17}$.

2. "Method of Numbers"18.

The A4 sheet shows 2 large squares. Each square has 16 small squares with numbers from 1 to 16 written in them (table 2).

Table 2. Example of a blank in the "Method of Numbers" test

\begin{tabular}{|c|c|c|c|}
\hline 4 & 9 & 14 & 11 \\
\hline 16 & 1 & 2 & 6 \\
\hline 13 & 8 & 15 & 3 \\
\hline 5 & 12 & 7 & 10 \\
\hline
\end{tabular}

\begin{tabular}{|c|c|c|c|}
\hline 15 & 14 & 2 & 7 \\
\hline 3 & 5 & 8 & 10 \\
\hline 12 & 9 & 13 & 16 \\
\hline 1 & 11 & 6 & 4 \\
\hline
\end{tabular}

Schoolchildren should switch their attention from square to square so that they can cross out the numbers in turn, first in the left square (number 1), then in the right square (number 1). The exercise ends when the schoolchildren has crossed out number 16 in both squares. Result: the time that children spent on completing the task ( 0.1 seconds).
Statistical Analysis: The results of the pedagogical experiment were processed using Microsoft excel 2016, which allows you to determine the average value of the indicators of both groups. The bio-stat 2009 program allows us to compare groups and determine the reliability of the results $(\mathrm{P}<0.05)$ using the $\mathrm{t}$-student parametric criterion $^{19}$.

\section{Results}

Before the beginning of the pedagogical research, all 40 schoolchildren took control tests. It should be noted that before the study, the differences in indicators between schoolchildren were not significant $(\mathrm{P}>0.05)$. After the study, the indicators changed in both classes (table 3).

Table 3 shows that the performance of schoolchildren from CG and EG improved in both tests. However, the improvement in both tests was different. In children in grade $3 \mathrm{~A}$ who were engaged in the standard physical education program at school, the performance in the «Shuttle run» test improved from $10.2 \pm 0.6$ to $9.9 \pm 0.5$ $(\mathrm{P}>0.05)$. Schoolchildren who were engaged in the standard program and performed the exercise Classics in each lesson improved their coordination abilities from $9.9 \pm 0.5$ to $8.5 \pm 0.4(\mathrm{P}<0.05)$. In the same way, the pedagogical experiment affected the indicators of switching the attention of schoolchildren. Children from $\mathrm{CG}$ in the «Method of Numbers» test had $5.4 \%$ higher scores $(\mathrm{P}>0.05)$, and children from EG had $26.6 \%$ better scores $(\mathrm{P}<0.05)$. Thus, we can talk about the insignificant effectiveness of the standard physical education program in secondary schools for the development of coordination abilities, and the introduction of exercise Classics in the educational process in physical education has a significant and positive effect on both coordination abilities and the ability of schoolchildren to switch attention.

Table 3. Indicators of coordination abilities and abilities of children 9-10 years old to switch attention

\begin{tabular}{|l|c|c|c|c|c|c|c|c|}
\hline \multirow{2}{*}{ Test } & \multicolumn{4}{|c|}{ CG } & \multicolumn{4}{c|}{ EG } \\
\cline { 2 - 9 } & Before & After & \% & P & Before & After & \% & P \\
\hline Shuttle run 3x10 m (s) & $10.2 \pm 0.6$ & $9.9 \pm 0.5$ & 2.9 & $\mathrm{P}>0.05$ & $9.9 \pm 0.5$ & $8.5 \pm 0.4$ & 14.1 & $\mathrm{P}<0.05$ \\
\hline Method of Numbers (s) & $44.1 \pm 3.4$ & $41.7 \pm 4.1$ & 5.4 & $\mathrm{P}>0.05$ & $42,9 \pm 3.9$ & $31.5 \pm 3.3$ & 26.6 & $\mathrm{P}<0.05$ \\
\hline
\end{tabular}




\section{Discussion}

Physical culture is very important for a person. The main goal of physical education is comprehensive personal development, preparation for work and life in society. Physical education classes at school are mandatory and make a significant contribution to the development of schoolchildren ${ }^{1-2}$.

Today, the physical education program at school is a set of method, sets of exercises and rules. Some authors believe that the modern physical education program is outdated and should be replaced with modern methodics and sets of exercises. However, in our opinion, this is a very strict measure. It is enough to add only a little to the program, for example, exercise Classics which has proved to be positive in previous studies ${ }^{6}$.

This study is new, as it is the first to study the influence of exercise Classics on the ability of schoolchildren to switch their attention. The relationship was positive. Children who performed the exercise Classics in every physical education lesson at school improved their ability to switch their attention.

Such studies confirm the data that physical culture, exercise and sport have a positive impact on the human body not only in terms of physical fitness, but also intellectual development ${ }^{14-15,20-21}$, such children have an advantage in solving tasks that require increased mental readiness, respectively, receive more positive ratings for their abilities ${ }^{16,22}$.

It should be noted that the authors' opinion about a favorable period for the development of coordination abilities of primary school children is fully confirmed by this study, since children in the control group who did not take additional classes were able to improve their indicators of coordination abilities ${ }^{12-13}$.

An individual approach to working with children is used more often in high school, and in primary school age, the method of differentiated approach is more common, which also proved itself in a new study ${ }^{7-8}$.

\section{Conclusion}

Thus, if you perform exercise Classics at each physical education lesson at school, the indicators of physical and mental development of children will improve. Specifically, indicators of coordination abilities and ability to switch attention. The new research is relevant and promising for further directions in the study of mental processes and physical abilities of schoolchildren.

Conflicts of Interest: There is no conflict of interest

Source of Funding: Self-funding

Ethical Clearance: All procedures performed in studies involving human participants were in accordance with the ethical standards of the institutional and/or national research committee and with the 1964 Helsinki declaration and its later amendments or comparable ethical standards. Informed consent was obtained from all individual participants included in the study.

\section{Reference}

1. Wallhead T, Garn A, Vidoni C. Sport Education and social goals in physical education: relationships with enjoyment, relatedness, and leisure-time physical activity. Physical Education and Sport Pedagogy 2012; 18(4):427-441. https://doi.org/10. 1080/17408989.2012.690377

2. Chen S, Kim Y, Gao Z. The contributing role of physical education in youth's daily physical activity and sedentary behavior. BMC Public Health 2014; 14. https://doi.org/10.1186/1471-2458-14-110

3. Lyakh VI. Physical culture. Grades 1-4: Textbook for general education institutions. - Moscow: Education. 2013; 190 p.

4. Chiodera P, Volta E, Gobbi G, Milioli MA, Mirandola P, Bonetti A, Delsignore R, Bernasconi S, Anedda A, Vitale M. Specifically designed physical exercise programs improve children's motor abilities. Scandinavian Journal of Medicine and Science in Sports 2008; 18(2):179-187. https:// doi.org/10.1111/j.1600-0838.2007.00682.x

5. Dobbins M, Husson H, DeCorby K, LaRocca RL. School-based physical activity programs for promoting physical activity \& fitness in children and adolescents aged 6 to 18 . Cochrane Database of Systematic Reviews 2013; 2. https://doi. org/10.1002/14651858.CD007651.pub2

6. Polevoy GG. Development of Coordination Abilities with Use of Classic's Exercises. International Journal of Medical Research \& Health Sciences 2019; 8 (12): 41-45

7. Barker D, Quennerstedt M, Annerstedt C. Learning through group work in physical education: a symbolic interactionist approach. Sport, Education 
and Society 2015; 20(5):604-623. https://doi.org/1 $0.1080 / 13573322.2014 .962493$

8. Kühnhausen J, Dirk J, Schmiedek F. Individual classification of elementary school children's physical activity: A time-efficient, group-based approach to reference measurements. Behaviour Research Method 2016; 49(2):685-697. DOI: 10.3758/s13428-016-0724-2

9. Bokin, A. Influence of coordination abilities of young karatekas on productivity of their sports activity. Social-economic phenomenons and process 2013; 12(58):198-201. DOI: 10.3200/ JMBR.40.5.400-408

10. Tuchak O. Influence of Coordination Exercises on Elementary Schoolchildren with Mental Retardation. Novelty. Physical Education, Sports and Health Culture in Modern Society 2018; 42(2):78-85. https://doi.org/10.29038/2220-74812018-02-78-85

11. Erceg M, Zagorac N, Katić R. The impact of football training on motor development in male children. Collegium antropologicum 2008; 32(1):241-247.

12. Matulaitis K, Skarbalius, A. Study of the Phenomenon of Sensitive Periods for Development of Velocity and Agility in Young Basketball Players (Aged 7-17). Theory and Practice of Physical Culture 2013; 1 .

13. Charles HZ, Megan RG, Robert BM, Jana MK, Nathan AF. Sensitive Periods. Monographs of the society for research in child development 2011; 76(4):147-162. http://doi.org/10.1111/j.15405834.2011.00631.x

14. Bidzan-Bluma I, Lipowska M. Physical Activity and Cognitive Functioning of Children. International journal of environmental research and public health 2018; 15(4):800 http://doi.org/10.3390/ ijerph15040800

15. Pietsch, S, Böttcher, C, Jansen P. Cognitive Motor Coordination Training Improves Mental Rotation Performance in Primary School-Aged Children.
Mind, Brain, and Education 2017; 11(4):176-180 https://doi.org/10.1111/mbe.12154

16. Esteban-Cornejo I, Tejero-González CM, Martinez-Gomez D, Cabanas-Sánchez V, Fernández-Santos JR, Conde-Caveda J, Sallis JF, Veiga OL. Objectively measured physical activity has a negative but weak association with academic performance in children and adolescents. Journal Acta Paediatrica 2014; 103(11):501-506. https:// doi.org/10.1111/apa.12757

17. Polevoy GG. Training of motor rhythm in students, practicing football. Physical education of students 2017; 21 (4):189-192. https://doi. org/10.15561/20755279.2017.0407

18. Nemov R.S. Psychology. Psychodiagnostics. Introduction to scientific psychological research with elements of mathematical statistics - Moscow: Vlados 2003; $640 \mathrm{p}$

19. Khusainova RM, Shilova ZV, Curteva OV. Selection of appropriate statistical method for research results processing. Mathematics Education 2016; 11(1):303-315. DOI: 10.12973/ iser.2016.21030a

20. Gerber M, Kalak N, Lemola S, Clough PJ, Pühse $\mathrm{U}$, Elliot S, Holsboer-Trachsler E, Brand S. Adolescents' exercise and physical activity are associated with mental toughness. Mental Health and Physical Activity 2012; 5(1): 35-42. https://doi. org/10.1016/j.mhpa.2012.02.004

21. Chang EC-H, Chu C-H, Karageorghis CI, Wang CC, Tsai JH-C, Wang Y-S, Chang Y-K. Relationship between mode of sport training and general cognitive performance. Journal of Sport and Health Science 2017; 6(1):89-95. https://doi. org/10.1016/j.jshs.2015.07.007

22. Trudeau F, Shephard RJ. School physical activity, school sports and academic performance. International Journal of Behavioral Nutrition and Physical Activity 2008, 5. https://doi. org/10.1186/1479-5868-5-10 